\title{
The Effect of End Effector Type Robot Training for Gait Disturbance of Brain Tumor Patients : Case Series
}

\author{
Minji Jung MD., Dae Yul Kim MD. \\ Department of Rehabilitation Medicine, Asan Medical Center \\ University of Ulsan College of Medicine, Seoul, Korea
}

Introduction Robot-assisted gait training is helpful in effectively implementing repetitive, high intensity gait training. Several studies have been conducted in different areas on robot assisted gait training, however there is little clinical research in the area of patients with brain tumor.

Purpose The purpose of this study is to investigate the effects of Morning Walk-assisted gait training for patients with brain tumor.

Methods We enrolled 10 patients with brain tumor, who have primary brain tumor, whose functional ambulation category (FAC) scores were $\geq 2$, and older than 18 years. Seven patients were dropped out because of deconditioning, recurred brain tumor, and early discharge, leaving a cohort of 3 for final analyses. Patients were treated with $30 \mathrm{~min}$ of Morning Walk training with $1 \mathrm{~h}$ of conventional physiotherapy, five times per week for 3 weeks.

Results Ten patients with primary brain tumor were enrolled. Seven patients were dropped out because of deconditioning $(\mathrm{N}=4)$, hydrocephalus $(\mathrm{N}=1)$, and early discharge $(\mathrm{N}=2)$ and leaving a cohort of 3 patients for final analyses. After training, most outcome measures significantly improved. The outcomes with the improved score in all three patients were $10 \mathrm{mWT}, \mathrm{MBI}$, RMI, BBS, and Karnofsky performance status scale. Four out of 7 patients were discontinued due to condition deterioration and fatigue. Tthe BFI index increased after treatment.

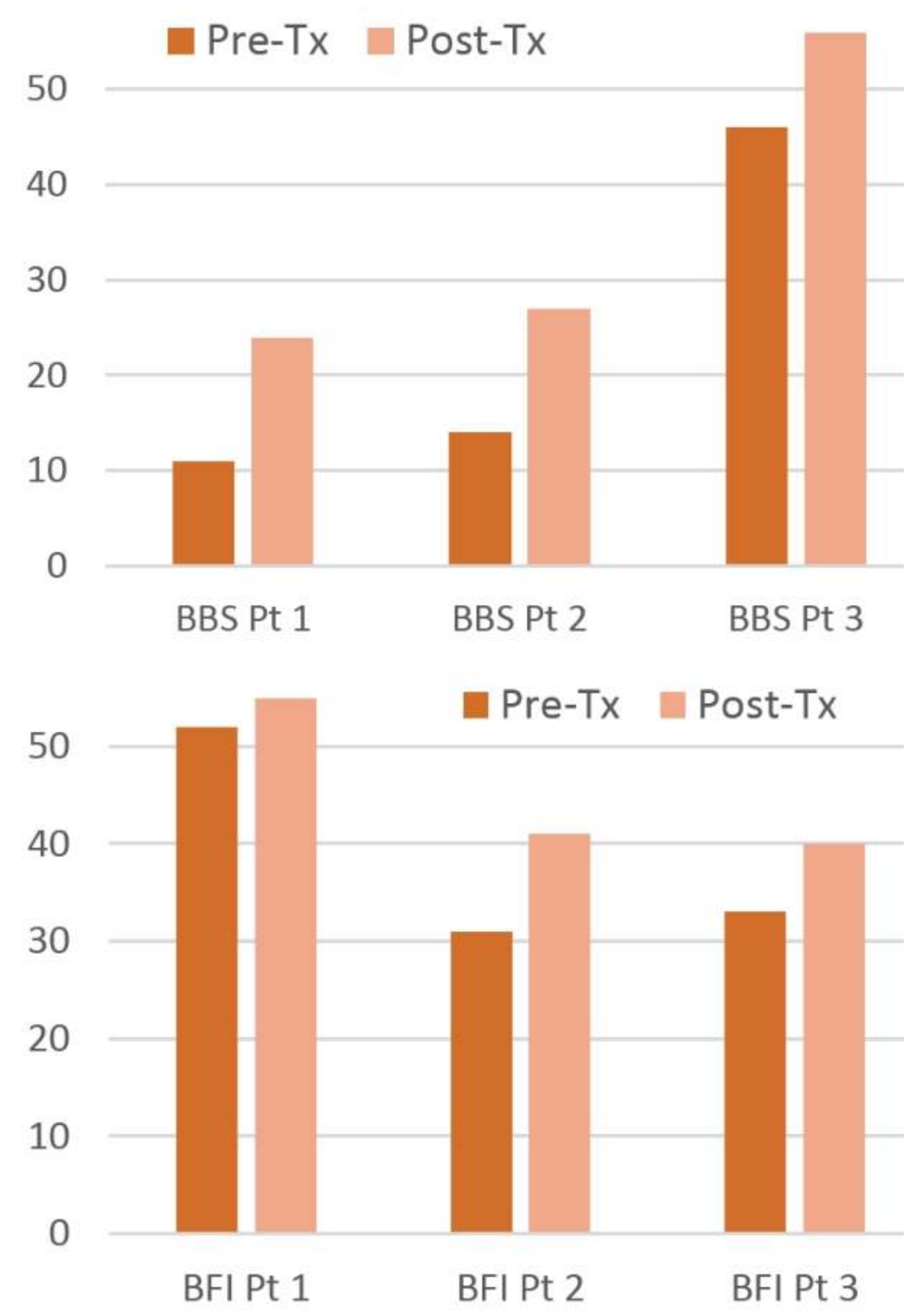

Conclusion After Morning Walk®-assisted gait training combined with conventional physiotherapy, several outcomes such as motricity of the affected limb, endurance, functional status and balance were improved, but the level of fatigue (BFI) was deteriorated in patients with brain tumor. Four out of the seven patients who were excluded from the study stopped the therapy due to deconditioning during treatment. Therefore, if you want to apply robot therapy to brain tumor patients, you need to keep in mind the degree of fatigue and adjust the treatment time, frequency of treatment, and intensity of exercise for patients. Further research is needed in this area with more numbers of patients and with randomized controlled studies.

Table 1. Participants' Characteristics

\begin{tabular}{|c|c|}
\hline & Patients \\
\hline Age (years) & $48.0 \pm 24.3$ \\
\hline \multicolumn{2}{|l|}{ Gender (n) } \\
\hline Male & 1 \\
\hline Female & 2 \\
\hline Height (cm) & $160.0 \pm 4.4$ \\
\hline Weight (kg) & $58.7 \pm 5.5$ \\
\hline BMI $\left(\mathrm{kg} / \mathrm{m}^{2}\right)$ & $22.9 \pm 1.9$ \\
\hline \multicolumn{2}{|l|}{ Tumor etiology } \\
\hline Astrocytoma & 1 \\
\hline LGG & 1 \\
\hline HGG & 1 \\
\hline \multicolumn{2}{|l|}{ Side of weakness } \\
\hline Left & 1 \\
\hline Right & 2 \\
\hline
\end{tabular}

Table 2. Changes of the Outcome Measures

\begin{tabular}{ccc|c}
\hline & Pre-Tx $\left(\mathrm{T}_{0}\right)$ & Post-Tx $\left(\mathrm{T}_{1}\right)$ & Difference $\left(\mathrm{T}_{1}-\mathrm{T}_{0}\right)$ \\
\hline FAC & $2.33 \pm 0.58$ & $3.33 \pm 1.53$ & $1.00 \pm 1.00$ \\
10mWT $(\mathrm{m} / \mathrm{s})$ & $0.64 \pm 0.49$ & $0.95 \pm 0.41$ & $0.31 \pm 0.08$ \\
K-MBI & $50.33 \pm 38.44$ & $80.00 \pm 22.34$ & $29.67 \pm 16.50$ \\
MI-Lower, affected limb & $74.33 \pm 26.54$ & $82.33 \pm 30.60$ & $8.00 \pm 13.86$ \\
RMI & $4.33 \pm 3.51$ & $7.67 \pm 3.06$ & $3.33 \pm 2.52$ \\
BBS & $23.67 \pm 19.40$ & $35.67 \pm 17.67$ & $12.00 \pm 1.73$ \\
Karnofsky & $46.67 \pm 11.55$ & $60.00 \pm 17.32$ & $13.33 \pm 5.77$ \\
BFI & $39.67 \pm 13.32$ & $45.33 \pm 8.39$ & $5.67 \pm 5.13$ \\
\hline
\end{tabular}

Values are presented as mean \pm SD, FAC, Functional Ambulation Category. $10 \mathrm{mWT}, 10 \mathrm{~m}$ Walk Test. MBI, Modified Barthel Index. MI-Lower, Motricity Index-lower. RMI, Rivermead Mobility Index. BBS, Berg Balance Scales. BFI, Brief Fatigue Index. 